ENCYCLOPEDDIE Encyclopédie berbère

BERBERE

5 | 1988

5 | Anacutas - Anti-Atlas

\title{
Antennes (monuments à)
}

Voir Abedni, Bazinas, Chapelles (monuments à)

E.B.

\section{OpenEdition}

Journals

Édition électronique

URL : http://journals.openedition.org/encyclopedieberbere/2520

DOI : 10.4000 /encyclopedieberbere.2520

ISSN : 2262-7197

Éditeur

Peeters Publishers

Édition imprimée

Date de publication : 1 avril 1988

Pagination : 710-712

ISBN : 2-85744-319-6

ISSN : $1015-7344$

Référence électronique

E.B., « Antennes (monuments à) », Encyclopédie berbère [En ligne], 5 | 1988, document A233, mis en ligne le 01 décembre 2012, consulté le 13 octobre 2020. URL : http://journals.openedition.org/ encyclopedieberbere/2520; DOI : https://doi.org/10.4000/encyclopedieberbere.2520

Ce document a été généré automatiquement le 13 octobre 2020

(c) Tous droits réservés 


\section{Antennes (monuments à)}

\section{Voir Abedni, Bazinas, Chapelles (monuments à)}

E.B.

Les archéologues donnent ce nom à des structures étroites et allongées, sortes de bras qui prolongent ou précèdent certains monuments protohistoriques en pierre sèche. Soit parce qu'elles y ont été mieux conservées, soit parce qu'il s'agit d'un fait culturel, les antennes sont surtout connues au Sahara.

Monument en croissant de l'Adrar Tiouiyne et monument en « aiguille de boussole » d'Akarakar (Ahaggar). Relevés G. Camps.
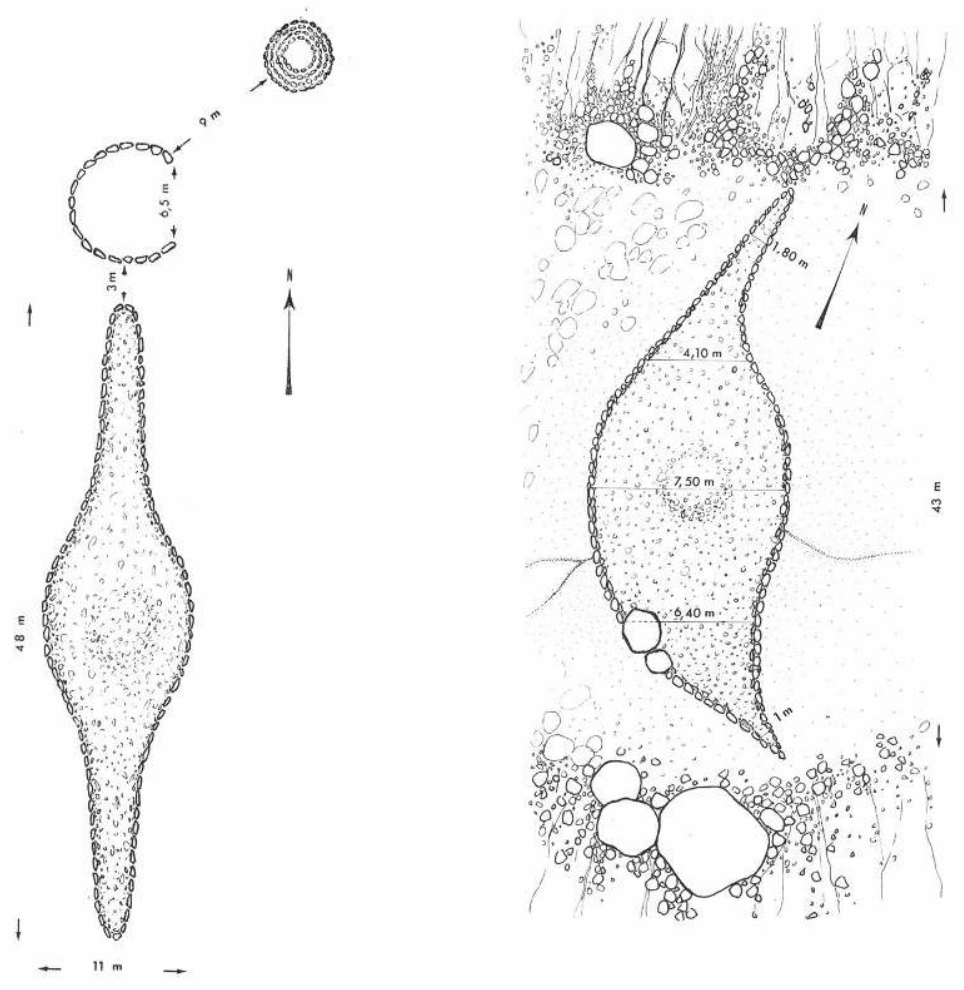
2 Les plus fréquentes sont disposées en $\mathrm{V}$; elles s'écartent de l'adebni* en déterminant un espace en forme d'éventail qui peut être considéré comme un téménos. Lorsque les antennes sont courtes et se dégagent progressivement du tumulus ou du dallage, on est en présence de monuments en croissant qui sont particulièrement nombreux en Ahaggar, mais ils sont connus aussi plus au nord, jusque dans l'Anti-Atlas. Une variété présente une disposition différente des antennes qui sont opposées; le monument ressemble alors à une aiguille de boussole, comme à Akarakar (Ahaggar). Dans les steppes du Haut Chélif on connaît aussi des bazinas* munies d'antennes ou de bras assez courts disposés de cette façon (Oued Ouerk). D'autres antennes, au contraire, ne sont faites que d'une rangée de pierres plantées dans le sol. Elles peuvent avoir une grande longueur ; on en a signalé qui dépassaient une centaine de mètres.

3 La fonction culturelle de ces antennes ne semble faire aucun doute: à Sila (Constantine), L. Frobenius avait reconnu un dolmen à deux caveaux muni d'antennes en $\mathrm{V}$, une niche culturelle occupait la partie de la paroi comprise entre les deux antennes. Ce monument permet de comprendre la genèse de certains monuments à chapelle* du Sahara occidental dont la "chapelle », destinée au culte funéraire et aux pratiques de l'incubation, était à l'origine constituée de deux antennes dont les extrémités se rebroussent à angle droit.

Bazina elliptique à antennes de l'oued Ouerk, d'après Roffo, et dolmen à niche et antennes de Sila, d'après L. Frobenius.

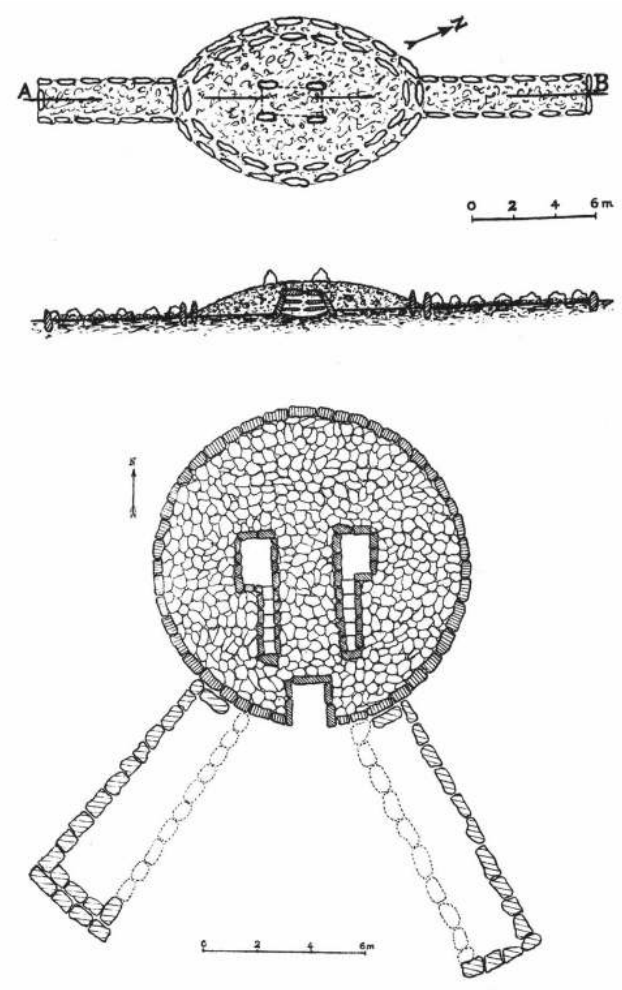


INDEX

Mots-clés : Architecture, Protohistoire, Rite 